\title{
Selectivity control in Pt-catalyzed cinnamaldehyde hydrogenation
}

\section{SUBJECT AREAS:}

HETEROGENEOUS

CATALYSIS

CATALYTIC MECHANISMS

Received

11 December 2014

Accepted

3 March 2015

Published

24 March 2015

Correspondence and requests for materials should be addressed to A.F.L. (a.f.lee@aston. ac.uk)

\author{
Lee J. Durndell', Christopher M. A. Parlett', Nicole S. Hondow', Mark A. Isaacs', Karen Wilson' \\ \& Adam F. Lee'
}

'European Bioenergy Research Institute, Aston University, Birmingham B4 7ET, UK, ${ }^{2}$ Institute for Materials Research, University of Leeds, Leeds LS2 9JT, UK.

Chemoselectivity is a cornerstone of catalysis, permitting the targeted modification of specific functional groups within complex starting materials. Here we elucidate key structural and electronic factors controlling the liquid phase hydrogenation of cinnamaldehyde and related benzylic aldehydes over Pt nanoparticles. Mechanistic insight from kinetic mapping reveals cinnamaldehyde hydrogenation is structure-insensitive over metallic platinum, proceeding with a common Turnover Frequency independent of precursor, particle size or support architecture. In contrast, selectivity to the desired cinnamyl alcohol product is highly structure sensitive, with large nanoparticles and high hydrogen pressures favoring $\mathrm{C}=\mathrm{O}$ over $\mathrm{C}=\mathrm{C}$ hydrogenation, attributed to molecular surface crowding and suppression of sterically-demanding adsorption modes. In situ vibrational spectroscopies highlight the role of support polarity in enhancing $\mathrm{C}=\mathrm{O}$ hydrogenation (through cinnamaldehyde reorientation), a general phenomenon extending to alkyl-substituted benzaldehydes. Tuning nanoparticle size and support polarity affords a flexible means to control the chemoselective hydrogenation of aromatic aldehydes.

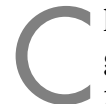

hemoselectivity is a cornerstone of catalysis, permitting the targeted modification of specific functional groups within complex starting materials ${ }^{1-5}$. This ability to activate and transform only certain chemical functionalities without the use of protecting groups, and attendant improvements in atom efficiency (and waste minimisation), also underpins catalysis' green credentials ${ }^{6-8}$. Catalytic hydrogenation of organic compounds possessing multiple unsaturated bonds such as $\alpha, \beta$-unsaturated aldehydes is particularly challenging ${ }^{9-12}$, necessitating active sites able to discriminate closely related moieties, and in some instances achieve preferential activation of a more thermodynamically stable function. Platinum is widely employed in heterogeneous catalytic hydrogenation, able to reduce a plethora of functional groups, including $\mathrm{C}=\mathrm{C}^{13}, \mathrm{C} \equiv \mathrm{C}^{14}, \mathrm{C}=\mathrm{O}^{15}, \mathrm{C} \equiv \mathrm{N}^{16}, \mathrm{NO}_{2}{ }^{17}$ and aromatics ${ }^{18}$ with molecular hydrogen. Selective hydrogenation of allylic and benzylic aldehydes to unsaturated alcohols is a commercially important industrial process widely utilised within the flavor and fragrance, agrochemical, and pharmaceutical sectors ${ }^{10,19}$, however the development of requisite heterogeneous catalysts has been hindered by the thermodynamic stability of $\mathrm{C}=\mathrm{O}$ relative to $\mathrm{C}=\mathrm{C}$ bonds and lack of insight into fundamental structure-function relations ${ }^{10}$.

Tsang and co-workers attempted to elucidate the roles of geometric and electronic effects in Pt catalyzed cinnamaldehyde (CinnALD) hydrogenation to cinnamyl alcohol (CinnOH) through studies of oleic acid/oleylamine stabilised mono- and bimetallic colloidal Pt nanoparticles. Selectivity towards CinnOH exhibited a strong dependence on Pt nanoparticle size, with low coordination sites favoring $\mathrm{C}=\mathrm{C}$ hydrogenation ${ }^{20,21}$. In contrast, Zhu and Zaera found that CinnOH selectivity was insensitive to the size of silica supported Pt nanoparticles ${ }^{22}$, although rates of CinnALD hydrogenation were structure sensitive, with (111) facets prevalent on larger particles accounting for a five-fold increase in Turnover Frequency (TOF) between 1.3 and $2.4 \mathrm{~nm}$ particles. Bimetallic catalysts formed via either one-pot synthesis or doping of Pt nanoparticles ${ }^{20,21,23,24}$, can afford enhanced selectivity to $\mathrm{CinnOH}$, although decoupling the role of promoters in blocking unselective sites versus electronic modification of platinum itself has not proved possible. Surface science studies of crotonaldehyde, an aliphatic analogue of CinnALD, have demonstrated that the molecular adsorption geometry is critical in directing final product selectivity over $\mathrm{Pt}(111)$ surfaces, with high coverages lifting the $\mathrm{C}=\mathrm{C}$ bond and tilting the $\mathrm{C}=\mathrm{O}$ bond with respect to the surface ${ }^{25,26}$. In an extension of this concept, thiolate adsorption onto Pt surfaces ${ }^{27}$ has been employed to achieve selective $\mathrm{C}=\mathrm{O}$ activation ${ }^{28}$, with phenylated thiols facilitating tunable, specific non-covalent interactions with CinnALD and consequent molecular orientation with respect to the surface of $\mathrm{Pt} / \mathrm{Al}_{2} \mathrm{O}_{3}$ catalysts thereby boosting $\mathrm{CinnOH}$ selectivity by $70 \%$. This promotion was attributed to $\pi$-stacking interactions between 
self-assembled monolayers of such thiols and the phenyl ring of CinnALD, which did not compromise the rate of product forma$\operatorname{tion}^{28}$. Guo et al. have shown that confinement of Pt nanoclusters within the cavity of metal-organic frameworks also promotes CinnOH selectivity; steric constraints on the CinnALD geometry is believed to hinder $\mathrm{C}=\mathrm{C}$ planar adsorption, again promoting $\mathrm{C}=\mathrm{O}$ activation $^{29}$. Despite this progress, kinetics of the CinnALD hydrogenation reaction network have not yet been mapped in detail over any heterogeneous catalyst, while for platinum there has been no systematic study on the impact of particle size (over a wide range) or $\mathrm{H}_{2}$ pressure, or of support properties which influence not only CinnALD hydrogenation ${ }^{30}$ but also crotonaldehyde ${ }^{31}$ and citral hydrogenation ${ }^{32,33}$. Consequently the nature of the active site remains a matter for speculation, and little is known regarding the effect of substituents, or the extent to which mechanistic models can be extended to other conjugated aldehydes.

Here, we resolve the preceding controversies, elucidating the reaction mechanism and kinetic pathways for CinnALD selective hydrogenation over two families of silica supported catalysts of tailored hydrophilicity and Pt nanoparticle size. To this end, the bulk and surface properties of nanoparticles and silica supports were characterised by XPS, XRD, HRTEM, SEM, CO chemisorption, DRIFTS, ATR-IR and porosimetry. Kinetic profiling revealed that CinnALD hydrogenation was structure insensitive, proceeding equally well over small $(<2 \mathrm{~nm})$ or large $(\sim 15 \mathrm{~nm})$ particles, however $\mathrm{C}=\mathrm{O}$ hydrogenation was profoundly structure sensitive, requiring large metal ensembles. Complementary in situ powder XRD and operando ATR-IR measurements provided valuable insight into the respective roles of hydrogen pressure and support functionality in regulating $\mathrm{C}=\mathrm{O}$ versus $\mathrm{C}=\mathrm{C}$ hydrogenation, with the resulting insight successfully predicting the behaviour of $\alpha$-methyl-trans-cinnamaldehyde and benzylic aldehyde hydrogenation over Pt catalysts, highlighting the generality of the concepts identified.

\section{Results and Discussion}

Catalyst characterization. Successful genesis of a hexagonal close packed $p 6 \mathrm{~mm}$ pore architecture within the parent mesoporous silica support (characteristic of SBA-15) was confirmed by low angle powder X-ray diffraction (Figure S1). Nitrogen porosimetry also demonstrated type IV isotherms with type $\mathrm{H} 1$ hysteresis as expected for SBA-15, with a BET surface area, mean BJH pore size and narrow mesopore size distributions consistent with literature values (Table $\mathrm{S} 1)^{34,35}$. The fumed silica exhibited a type II isotherm, indicating a non-porous or macroporous material, and low BET surface area. HRTEM shown in Figure S2 confirmed the ordered mesopore network of SBA-15. Complimentary measurements on the two Pt-

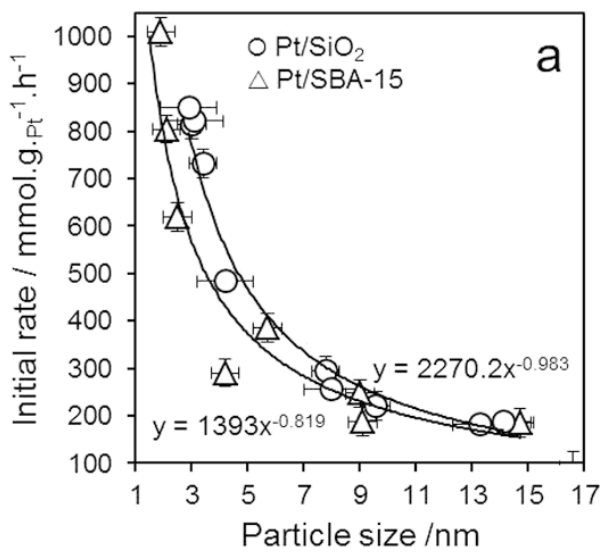

impregnated silica families evidenced pore arrangements and mesopore diameters comparable to those of the parent SBA-15 and fumed silica (Table S2). However, BET surface areas decreased for both supports with increasing $\mathrm{Pt}$ loading, with the Pt/SBA-15 materials exhibiting the greatest loss (up to 20\%), which we attribute to micropore blockage consistent with t-plot analysis in Table S2. Such surface area losses are in quantitative agreement with those reported following $\mathrm{Pd}$ impregnation of the same supports $^{35}$. The smaller loss in surface area for the $\mathrm{Pt} / \mathrm{SiO}_{2}$ materials was consistent with deposition of platinum nanoparticles predominantly over the (proportionately larger) external surface area of the fumed support.

Wide angle powder XRD (Figure S4) revealed exclusively fcc platinum metal over both silicas. Platinum nanoparticle sizes estimated from these reflections increased with loading, from $5.4 \mathrm{~nm}(0.5 \mathrm{wt} \%)$ to $15 \mathrm{~nm}(2 \mathrm{wt} \%)$ for Pt/SBA-15, and 8.4 to $17 \mathrm{~nm}$ for the analogous $\mathrm{Pt} /$ silicas; larger crystallites are expected for the latter due to the lower surface area of the fumed silica. The size, dispersion and oxidation state (Table S2, Figure S6) of silica supported platinum nanoparticles were sensitive to metal loading. Nanoparticle diameter increased linearly with Pt loading over both silicas (Figure S6a), while platinum dispersion (surface $\mathrm{Pt}^{0}$ content) decreased (increased) monotonically with diameter between 2 and $8 \mathrm{~nm}$ before reaching a plateau for larger sizes (Figure S6b). Platinum dispersion and surface oxidation state were solely a function of nanoparticle size for both fumed and mesoporous silicas, irrespective of whether nitrate or chloride precursor were employed, consistent with the generallyheld view of silica as a weakly interacting support; no unusual $\mathrm{Pt}$ redispersion was observed, as has been postulated via $\mathrm{Pt}(\mathrm{IV}) \mathrm{Cl}_{\mathrm{x}}$ surface complexes when using a hexachloroplatinic acid precursor ${ }^{36}$.

Cinnamaldehyde hydrogenation. The selective hydrogenation of CinnALD was subsequently studied over both $\mathrm{Pt} / \mathrm{SiO}_{2}$ and $\mathrm{Pt} / \mathrm{SBA}$ 15 catalyst series (Figure S7-14). Initial hydrogenation rates fell dramatically with increasing nanoparticle size (Figure 1a), exhibiting an inverse proportionality with particle diameter, precisely as would be anticipated if reactivity was dictated solely by the geometric platinum surface area, irrespective of the local coordination number of surface atoms or electronic structure. This structure insensitivity is confirmed by calculating the corresponding TOFs for CinnALD hydrogenation (Figure 1b), derived by normalizing the initial rate to the surface density of metallic $\mathrm{Pt}$ atoms determined via $\mathrm{CO}$ chemisorption and XPS, which were particle size (and support and precursor) invariant at around $350 \mathrm{~h}^{-1}$ under 1 bar $\mathrm{H}_{2}$ for all catalysts. Apparent activation energies for the highest loading $\mathrm{Pt} / \mathrm{SiO}_{2}$ and Pt/SBA-15 catalysts were also identical at $21 \mathrm{~kJ} \cdot \mathrm{mol}^{-1}$, implicating a common reaction mechanism for CinnALD hydrogenation over both

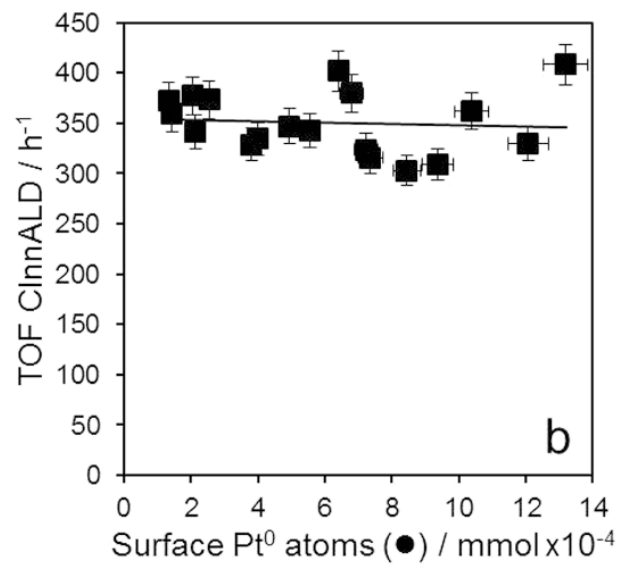

Figure 1 (a) Initial rate of CinnALD hydrogenation over silica supported platinum catalysts at 1 bar as a function of particle size; and (b) corresponding turnover frequencies for CinnALD hydrogenation. 


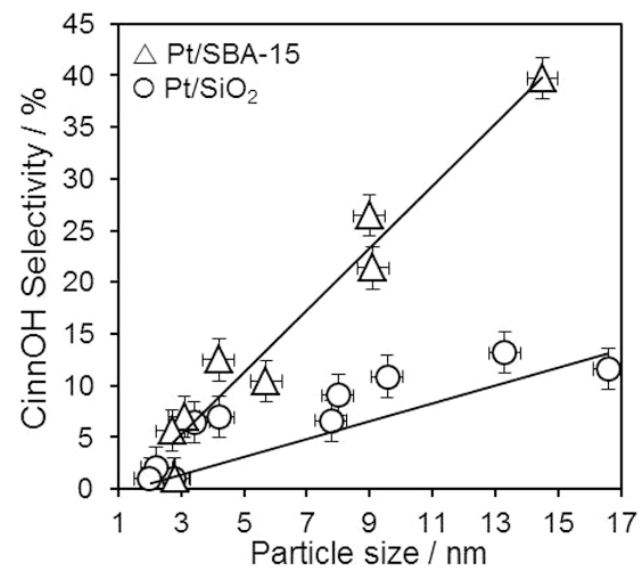

Figure $2 \mid$ CinnOH selectivity after $7 \mathrm{~h}$ CinnALD hydrogenation over silica supported platinum catalysts at $\mathbf{1}$ bar as a function of particle size.

supports. Similar TOFs between 200 and $350 \mathrm{~h}^{-1}$ have been reported for a narrow size distribution of platinum and ruthenium nanoparticles supported on carbon nanofibers in atmospheric pressure CinnALD hydrogenation ${ }^{37}$. However, this finding stands in contrast to a recent report of room temperature CinnALD hydrogenation at 10 bar $\mathrm{H}_{2}$ over $\mathrm{Pt} /$ Aerosil silica catalysts, for which the TOF increased from 396 to $1836 \mathrm{~h}^{-1}$ with increasing Pt particle size over the narrow range from 1.3 to $2.4 \mathrm{~nm}^{22}$; albeit, this previous study noted significant errors in both activity and nanoparticle size, relying upon indirect estimates of the surface Pt atom density via TEM from which to determine TOFs. Considering the systematic behavior of the 18 different Pt/silica catalysts in the present work, we find no evidence that CinnALD hydrogenation is favoured over flat surfaces present on larger platinum nanoparticles. The inverse proportionality of CinnALD hydrogenation initial rate on particle size is consistent with a direct correlation between activity and the geometric surface $\mathrm{Pt}$ atom density, i.e. the rate of cinnamaldehyde hydrogenation depended solely on the surface area:volume ratio $\left(\propto\right.$ particle diameter ${ }^{-1}$ ), with no preference for specific platinum facets. The latter also suggests that all catalysts underwent rapid in situ reduction to present a similar, metallic platinum surface species exhibiting similar electronic structure.

By comparison, selectivity towards the desired $\mathrm{CinnOH}$ product was strongly dependent on particle size and support morphology (Figure 2), increasing linearly from essentially zero over the smallest ( $2 \mathrm{~nm}$ ) particles, to $12 \%$ and $40 \%$ for $15 \mathrm{~nm}$ particles on the fumed silica and mesoporous SBA-15 supports respectively. Identical trends were observed during the first hour of reaction (Figure S12). This particle size dependence is consistent with a number of previous reports for $\mathrm{Ru}^{38,39}, \mathrm{Co}^{40}$ and $\mathrm{Pt}^{20,37,41}$ catalysts, and is generally attributed to an increase in the density of Pt (111) facets relative to lower coordination sites over larger nanoparticles, which hamper close approach of the $\mathrm{C}=\mathrm{C}$ bond and hence favour $\mathrm{C}=\mathrm{O}$ hydrogenation $^{20,21,42,43}$. This hypothesis is supported by extended Hückel calculations of Delbecq and Sautet which revealed that di- $\sigma_{\mathrm{CC}}$ CinnALD adsorption is strongly destabilised over $\mathrm{Pt}(111)$ facets with respect to a di- $\sigma_{\mathrm{CO}}$ mode, and hence favour $\mathrm{C}=\mathrm{O}$ hydrogenation, in comparison with $\mathrm{Pt}(100)$ and stepped facets which stabilise a co-planar $\eta_{4}$ di- $\sigma_{\mathrm{CO}}+\pi_{\mathrm{C}=\mathrm{C}}$ or trihapto $\pi_{\mathrm{C}=\mathrm{C}}+(\mathrm{O})$ mode, and hence favour $\mathrm{C}=\mathrm{C}$ hydrogenation ${ }^{44}$. Recent DFT calculations indicate that the activation barrier to $\mathrm{C}=\mathrm{C}$ hydrogenation of allylic aldehydes and ketones over $\mathrm{Pt}(111)$ remains lower than that of $\mathrm{C}=\mathrm{O}$ hydrogenation, but also suggest that phenyl substitution $\alpha$ to the $\mathrm{C}=\mathrm{C}$ bond should slow its rate of hydrogenation ${ }^{45}$. This body of literature stands in contrast to the high pressure study of Zhu and Zaera ${ }^{22}$, who reported a similar low initial selectivity $(\sim 20 \%)$ towards $\mathrm{CinnOH}$ over Pt/Aerosil silica to that in the present work, but surprisingly found this selectivity insensitive to particle size or CinnALD conversion (below $80 \%$ ) for sub $2.4 \mathrm{~nm}$ nanoparticles.

Other major reaction products were 3-phenyl propionaldehyde $>$ 3-phenyl propan-1-ol > ethylbenzene: high selectivity to the saturated aldehyde demonstrates that undesired $\mathrm{C}=\mathrm{C}$ hydrogenation competes strongly with $\mathrm{C}=\mathrm{O}$ hydrogenation, with ethylbenzene a by-product of 3-phenyl propionaldehyde and/or 3-phenyl propan-1ol hydrogenolysis. CinnOH selectivity increased continuously over the course of reaction for all catalysts, doubling its value between 1 and $7 \mathrm{~h}$. This improved selectivity occurred at the expense of 3phenyl propionaldehyde and 3-phenyl propan-1-ol for the Pt/SBA15 and $\mathrm{Pt} / \mathrm{SiO}_{2}$ catalysts respectively (Figure S9). Note that the principal product during the early stage of reaction over $2 \mathrm{wt} \% \mathrm{Pt} / \mathrm{SiO}_{2}$ was 3-phenyl propan-1-ol, a secondary product arising from hydrogenation of either cinnamyl alcohol or 3-phenyl propionaldehyde. The absence of $\mathrm{CinnOH}$ primary product can be rationalised by considering that the rate of its hydrogenation (and hence removal from the reaction mixture) is $>40$ times faster than its initial rate of formation (see below), accounting for a very low $\mathrm{CinnOH}$ and high concentration of 3-phenyl propan-1-ol secondary product; onstream deactivation of this rapid $\mathrm{CinnOH}$ hydrogenation step would account for its subsequent accumulation at higher conversions. Literature in this regard is conflicted, with a strong product dependence on CinnALD conversion reported over $\mathrm{Pt}^{46}, \mathrm{Ir}^{47}$ and $\mathrm{Ru}^{39}$, while other researchers note minimal change in $\mathrm{CinnOH}$ selectivity for conversions $<80 \%^{20,37,48-50}$. From the present kinetic investigation we can conclude that $\mathrm{C}=\mathrm{C}$ hydrogenation is initially heavily favoured over Pt/SBA-15, but that this pathway is rapidly switched off during the early stages of CinnALD hydrogenation, possibly due to surface crowding by strongly bound adsorbates ${ }^{49}$.

The observed structure sensitivity of $\mathrm{CinnOH}$ selectivity upon $\mathrm{Pt}$ nanoparticle size seen in Figure 2 was five times greater for Pt/SBA15 catalysts. Since CinnALD hydrogenation proceeds with a common TOF over both supports, this difference cannot be readily ascribed to differential mass-transport (which should in any event favour more rapid removal of the reactively-formed CinnOH for $\mathrm{Pt} /$ $\mathrm{SiO}_{2}$, wherein reaction occurs largely on the external surface area, and hence higher selectivity to this desired product). Net $\mathrm{CinnOH}$ selectivity is a function of both the rate of $\mathrm{C}=\mathrm{O}$ (versus $\mathrm{C}=\mathrm{C}$ ) hydrogenation of the CinnALD reactant, and of secondary hydrogenation of the allylic alcohol product to 3-phenyl propanol. The preceding observations can only therefore be understood by also considering the support dependence of $\mathrm{CinnOH}$ hydrogenation; we therefore undertook parallel studies employing $\mathrm{CinnOH}$ and 3phenyl propionaldehyde as substrates.

Figure 3a highlights a dramatic difference in $\mathrm{CinnOH}$ reactivity over fumed silica versus SBA-15 supported Pt nanoparticles of similar loading $(\sim 2 \mathrm{wt} \%)$ and size $(\sim 15 \mathrm{~nm})$, in precisely the regime wherein the most significant differences in CinnALD hydrogenation to the alcohol were identified in Figure 2. However, the question remains as to whether the support also influences the rate of CinnOH formation. Selective hydrogenation studies of 3-phenyl propionaldehyde, the primary product resulting from CinnALD $\mathrm{C}=\mathrm{C}$ hydrogenation, revealed identical rates of its removal over both 2 wt\% catalysts (Figure 3b), and hence selectivity to this saturated aldehyde is determined only by the relative rates of CinnALD $\mathrm{C}=\mathrm{C}$ versus $\mathrm{C}=\mathrm{O}$ hydrogenation. Since $\mathrm{CinnALD}$ selectivity towards 3-phenyl propionaldehyde differs at 39\% (SBA-15) versus $51 \%\left(\mathrm{SiO}_{2}\right)$, we can conclude that the support does somewhat impact upon the rates of $\mathrm{C}=\mathrm{C}$ versus $\mathrm{C}=\mathrm{O}$ hydrogenation, and hence also influences the rate of $\mathrm{CinnOH}$ formation. In other words, the observed differences in selective hydrogenation of CinnALD to CinnOH over the fumed versus mesoporous supports are dominated by their differing reactivity towards the unsaturated alcohol primary product, but are also influenced by their interaction with CinnALD. The former finding is in excellent agreement with DFT calculations 

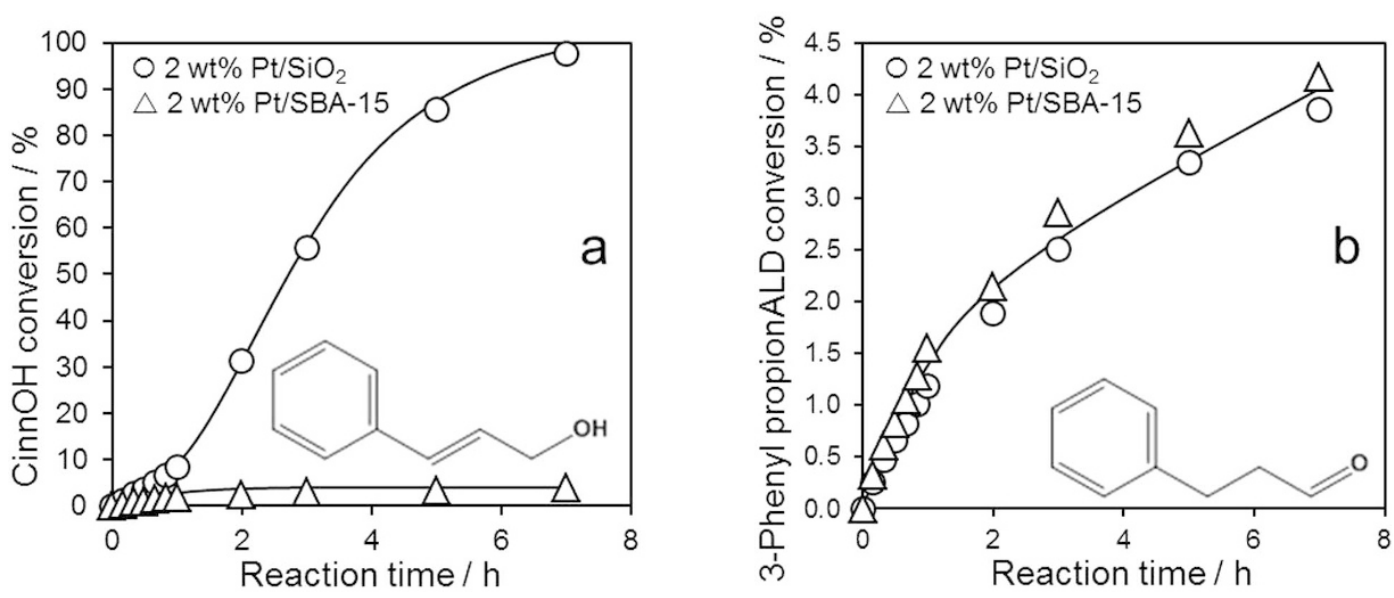

Figure 3 (a) CinnOH and (b) 3-phenyl propionaldehyde hydrogenation over $2 \mathrm{wt} \%$ silica supported platinum catalysts at 1 bar.

by Laref and co-workers for allylic aldehyde hydrogenation over $\mathrm{Pt}(111)$ model surfaces, which showed that selectivity to unsaturated alcohols is determined predominantly by the strength of their binding ${ }^{51}$.

A complete reaction network for CinnALD hydrogenation is shown in Figure 4 below, with reaction rates determined for each step over the highest loading Pt catalysts. This highlights the critical reactivity difference between the two silica supports, namely that fumed silica favor $\mathrm{C}=\mathrm{C}$ hydrogenation of both CinnALD and the desired CinnOH product, whereas SBA-15 is more selective towards $\mathrm{CinnOH}$ formation and suppresses its subsequent removal.

Support effects upon CinnALD hydrogenation and $\mathrm{CinnOH}$ selectivity have been noted for carbon ${ }^{30,50}$ and oxide ${ }^{46,52}$ supported Pt NPs. In the former case, annealed carbon nanofibers were postulated to produce non-polar surfaces favouring CinnALD adsorption via the benzene ring directly on the support; however, such nonpolar nanofibers were far less selective to $\mathrm{CinnOH}$ than their oxygen-rich, acidic counterparts. In contrast, Ji et al. recently reported graphene-based catalysts as more selective towards CinnOH than Vulcan carbon analogues ${ }^{30}$ which possess more polar surfaces ${ }^{53}$, attributed to the higher proportion of $\mathrm{Pt}$ metal present on graphene. Lewis acidic Al-SBA-15 and $\mathrm{Al}_{2} \mathrm{O}_{3}{ }^{46}$ supports also exhibit enhanced $\mathrm{CinnOH}$ selectivity, hypothesised due to preferential adsorption of the polar $\mathrm{C}=\mathrm{O}$ function at sites adjacent to $\mathrm{Pt}$ nanoparticles. In order to identify whether the differing reactivity of our fumed silica and SBA-15 supported platinum catalysts seen in Figure 2-3 was likewise a consequence of surface polarity, DRIFT spectra of the parent supports and high loading $\mathrm{Pt}$ catalysts were compared. Figure 5 highlights a striking difference in the silanol surface density and

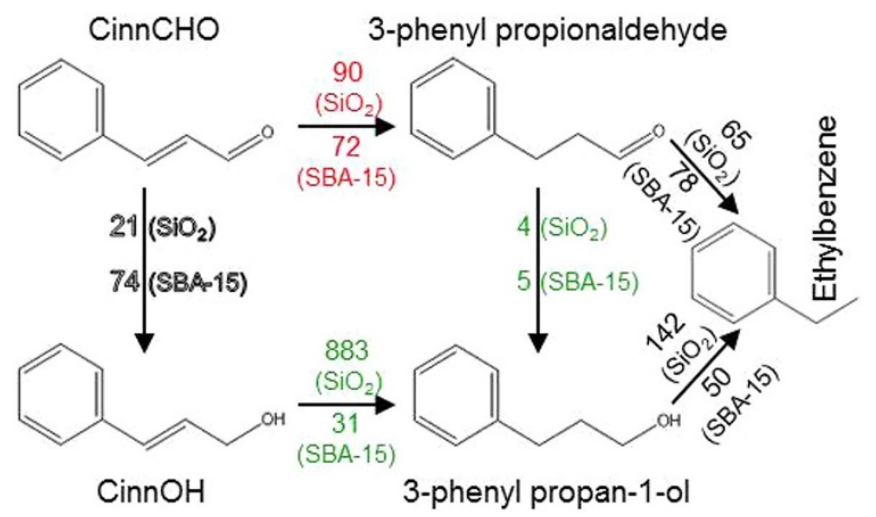

Figure 4 | Kinetic network for CinnALD hydrogenation over 2 wt\% Pt/ silica catalysts. Values refer to the initial rates of each step in mmol.h ${ }^{-1} \cdot \mathrm{g}_{\mathrm{Pt}}{ }^{-1}$. coordination mode between the two silica supports: mesoporous SBA-15 possesses almost twice the density of surface silanols of the fumed silica (3.0 vs. $1.6 \mathrm{mmol} . \mathrm{g}^{-1}$ respectively), and is dominated by geminal/vicinal silanol groups whereas fumed silica only exhibits isolated silanols. Vicinal silanols comprise extended, hydrogen bonded hydrophilic patches ${ }^{54}$, and hence our SBA-15 catalysts are indeed extremely polar compared to those prepared from fumed silica (whose hydrophobicity as a consequence of isolated silanols has been recently described $^{55}$ ). Since the physicochemical properties of Pt nanoparticles in terms of electronic charge (XPS), phase (XRD) and size (TEM/CO chemisorption) are essentially identical over both supports, it therefore seems entirely plausible that the higher selectivity to CinnOH of the Pt/SBA-15 arises from molecular re-orientation of the CinnALD reactant and/or reactively-formed hydrogenation products. Hence SBA-15 is expected to disfavour CinnALD and $\mathrm{CinnOH}$ adsorption geometries over platinum which require close approach of the apolar phenyl ring to the support surface, as necessary to effect $\mathrm{C}=\mathrm{C}$ hydrogenation at the nanoparticle-support perimeter, and conversely favour adsorption configurations in which the $\mathrm{C}=\mathrm{O}$ function is proximate to the support with the molecular plane oriented away from the surface. A similar concept has been advanced for crotonaldehyde (the aliphatic $\mathrm{C}_{4}$ analogue of CinnALD) over a $\mathrm{Pt}(111)$ single crystal wherein molecular tilting distances the $\mathrm{C}=\mathrm{C}$ bond from the surface while activating the $\mathrm{C}=\mathrm{O}$ bond towards hydrogenation ${ }^{28}$.

The preceding hypothesis was tested via an in situ ATR-IR study of CinnALD adsorption from a $0.84 \mathrm{M}$ anisole solution over films of 2 wt $\% \mathrm{Pt} / \mathrm{SiO}_{2}$ and $2 \mathrm{wt} \% \mathrm{Pt} / \mathrm{SBA}-15$ catalysts at $90^{\circ} \mathrm{C}$. This mimics the actual reaction conditions utilised during our catalytic studies of CinnALD hydrogenation, but without the presence of dissolved hydrogen and attendant complications arising from IR signatures due to hydrogenation products. Vibrational spectra over both catalyst films were temperature independent between room temperature and $90^{\circ} \mathrm{C}$, and exhibited characteristic $v_{\mathrm{C}}=\mathrm{O}$ and symmetric $\mathrm{v}_{\mathrm{C}=\mathrm{C}}$ bands of the parent CinnALD at 1678 and $1624 \mathrm{~cm}^{-1}$ respectively (Figure 6). However, a key difference is apparent in the aromatic $\mathrm{C}=\mathrm{C}$ regime, wherein bands at 1600 and $1594 \mathrm{~cm}^{-1}$ associated with the aromatic $\mathrm{C}=\mathrm{C}$ stretches are absent from $\mathrm{Pt}$ nanoparticles dispersed over the polar SBA-15 support, indicating loss of conjugation across CinnALD due to adsorption through the carbonyl function and associated molecular reorientation relative to that adopted on nanoparticles residing on the less polar fumed silica, consistent with the above model. CinnALD hydrogenation proceeds with a common apparent activation energy of $21 \mathrm{~kJ} \cdot \mathrm{mol}^{-1}$ over $2 \mathrm{wt} \% \mathrm{SBA}-15$ and fumed silica, supporting the notion that the differing selectivity of these catalysts reflects different modes of CinnALD adsorption over each support, rather than e.g. types of hydrogenation active sites. In summary, the higher selectivity of Pt/SBA-15 towards CinnOH dur- 


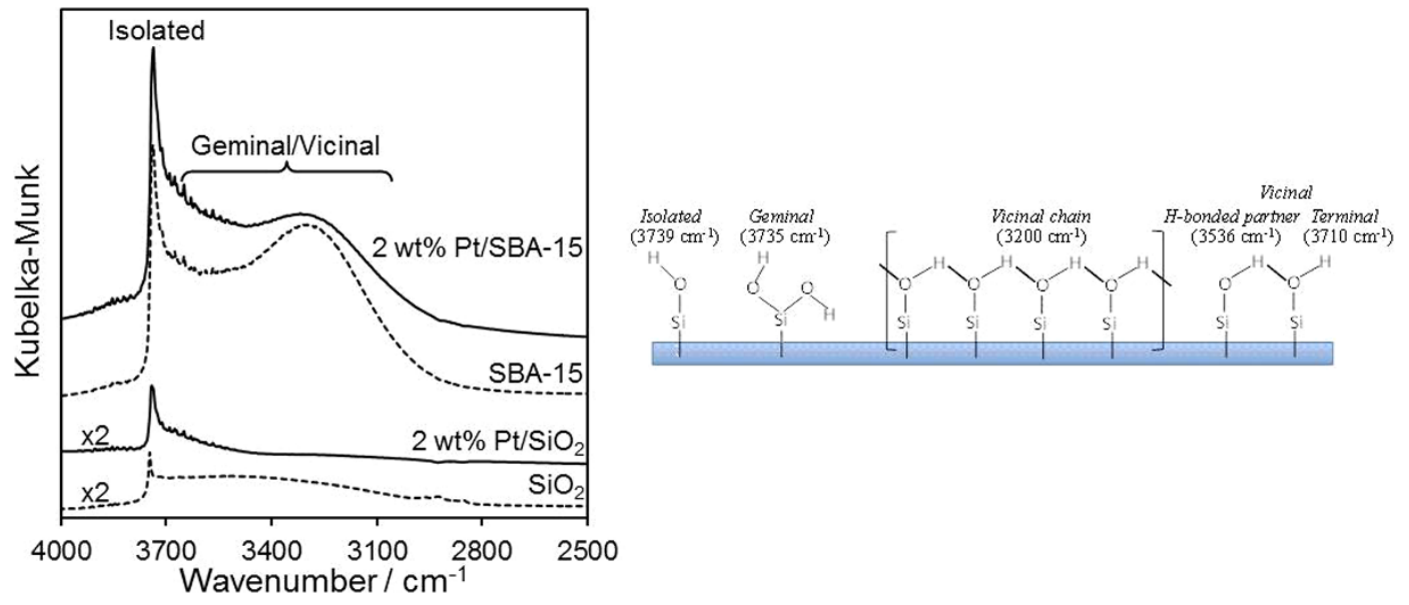

Figure 5 In vacuo DRIFT spectra of $2 \mathrm{wt} \%$ silica supported Pt catalysts dried at $200^{\circ} \mathrm{C}$; assignment of silanol functions and associated vibrational frequencies for silica surfaces.

ing CinnALD hydrogenation appears associated with a molecular reorientation of the phenyl ring due to repulsive interactions with surface silanols, facilitating preferential di- $\sigma_{\mathrm{CO}}$ adsorption and subsequent $\mathrm{C}=\mathrm{O}$ hydrogenation (illustrated in Figure 6).

Our proposition that polar supports favour selective $\mathrm{C}=\mathrm{O}$ hydrogenation of aromatic aldehydes (through molecular reorientation) was tested for the hydrogenation of benzylic aldehydes over the same $2 \mathrm{wt} \% \mathrm{Pt} / \mathrm{SBA}-15$ and $\mathrm{Pt} / \mathrm{SiO}_{2}$ catalysts. Figure 7 summarises the resulting performance, from which it is evident that the more polar $\mathrm{Pt} / \mathrm{SBA}-15$ outperforms the fumed silica support in respect of $\mathrm{C}=\mathrm{O}$ versus $\mathrm{C}=\mathrm{C}$ hydrogenation/hydrogenolysis for all substrates, as postulated. It has been speculated that methyl substituents stabilise adsorbed $\pi$-complexed aromatics resulting in higher barriers to ring hydrogenation ${ }^{56,57}$, rationalising the superior selectivity we observe towards alkyl-substituted benzylic alcohols versus benzyl alcohol. Surprisingly, Pt/SBA-15 was also more active towards all five benzylic aldehydes than $\mathrm{Pt} / \mathrm{SiO}_{2}$, whereas it was marginally less active towards CinnALD (13\% versus 19\% conversion respectively). This may be a consequence of faster desorption of the less polar benzylic products away from the SBA-15 surface. Figure 7 shows that electron-donating alkyl substituents accelerated benzaldehyde hydrogenation over both silica supports, presumably via activation of the carbonyl function (in addition to the aromatic ring).
Liquid phase catalytic hydrogenations typically exhibit strong positive reaction orders in hydrogen partial pressure, reflecting the increased availability of atomic hydrogen as a consequence of higher solubility (Henry's Law). The impact of hydrogen pressure upon CinnALD hydrogenation was therefore investigated over the most selective $2 \mathrm{wt} \% \mathrm{Pt} / \mathrm{SiO}_{2}$ and $\mathrm{Pt} / \mathrm{SBA}-15$ catalysts in a stirred batch autoclave under a constant hydrogen pressure between 1 and 10 bar. As anticipated, increasing the hydrogen pressure increased the initial rate and associated TOF of CinnALD hydrogenation (and final conversions) over both supported Pt catalysts (Figure S18). Similar trends have been reported for atmospheric ${ }^{37}$ versus high pressure (48 bar $)^{50}$ CinnALD hydrogenation over carbon nanofiber supported platinum, wherein TOFs rose from $\sim 200$ to $828 \mathrm{~h}^{-1}$ respectively. While the fumed silica proved slightly more pressure sensitive, the reaction order in $\mathrm{pH}_{2}$ only ranged from 0.4 to 0.6 between the two supports, close to the 0.5 value expected if the rate-determining step involves the reaction of CinnALD with a single hydrogen adatom originating from the dissociative adsorption of molecular $\mathrm{H}_{2}$ (as previously observed for reduced platinum nanoparticles over deoxygenated carbon nanofibers at ambient pressure ${ }^{50}$ ). The positive order in $\mathrm{pH}_{2}$ demonstrates that vacant surface sites remain available for dissociative chemisorption of hydrogen over the pressure range explored, with atomic hydrogen participating equally in the two
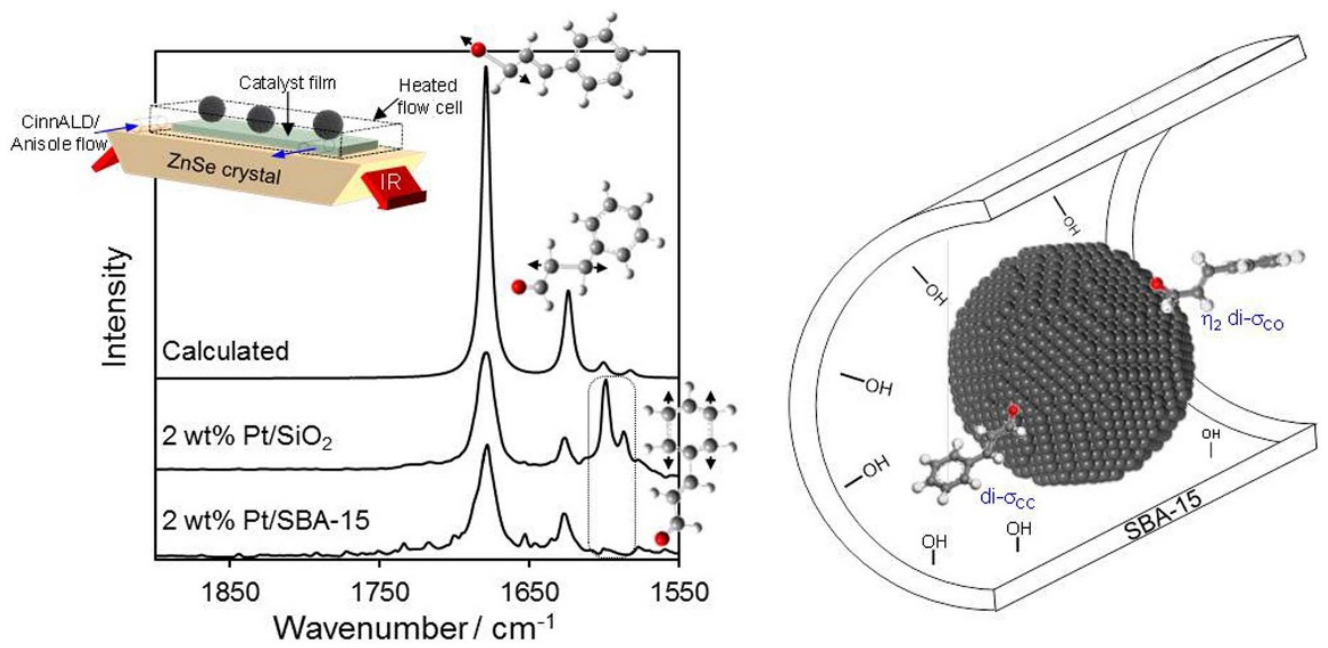

Figure 6 | (left) In situ ATR-IR spectra of $2 \mathrm{wt} \%$ silica supported Pt catalysts films under a flowing CinnALD/anisole solution at $90^{\circ} \mathrm{C}$ and (right) illustration of unfavorable aromatic-surface interaction arising from adoption of di- $\sigma_{\mathrm{CC}}$ versus di- $\sigma_{\mathrm{CO}}$ CinnALD adsorption on platinum nanoparticles within polar SBA-15 pores. 


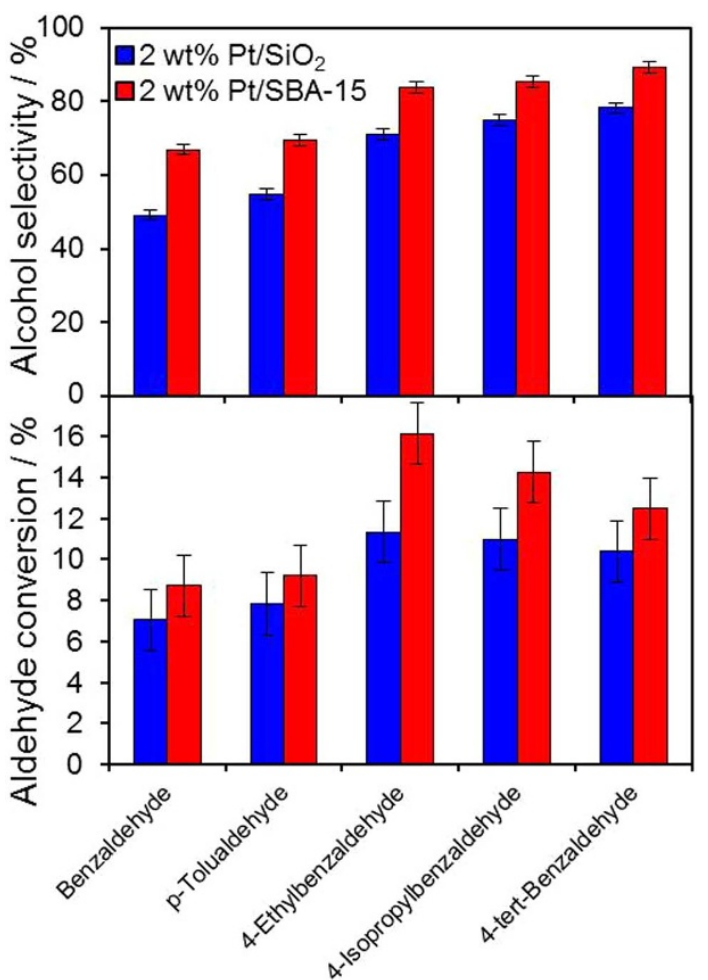

Figure $7 \mid$ Performance of $2 \mathrm{wt} \%$ silica supported Pt catalysts at $7 \mathrm{~h}$ for the hydrogenation of substituted benzaldehydes under standard reaction conditions employed for CinnALD hydrogenation.

competing pathways for CinnALD hydrogenation to $\mathrm{CinnOH}$ or 3phenyl propionaldehyde, evidenced by the independence of reaction order on product selectivity (see discussion below).

The influence of hydrogen pressure upon selectivity (Figure S13) was even more striking than on activity. Figure 8 reveals that CinnALD hydrogenation to $\mathrm{CinnOH}$ was favoured over both fumed silica and SBA-15 at higher pressures. Such enhanced selectivity at higher $\mathrm{pH}_{2}$ was reported for Co-doped Pt nanocrystals, though no explanation was given ${ }^{20}$. For the $2 \mathrm{wt} \% \mathrm{Pt} / \mathrm{SBA}-15$ catalyst, $\mathrm{CinnOH}$ selectivity exceeded $90 \%$ at 10 bar, accompanied by trace 3-phenyl propionaldehyde, while for the $2 \mathrm{wt} \% \mathrm{Pt} / \mathrm{SiO}_{2}$ selectivity rose to $56 \%$ (predominantly at the expense of ethylbenzene via 3-phenyl propanol hydrogenolysis, Figure S13). This switchover from $\mathrm{C}=\mathrm{C}$ to $\mathrm{C}=\mathrm{O}$ hydrogenation with increasing $\mathrm{pH}_{2}$ is best illustrated by comparing the ratio of $\mathrm{CinnOH}$ to 3-phenyl propionaldehyde, which increases 22 -fold over the SBA-15 support versus three-fold for the fumed silica, highlighting the greater sensitivity of the mesostructured catalyst to experimental conditions and its superior potential for $\mathrm{CinnOH}$ production. Comparison at a common conversion level reveals qualitatively similar trends (Table S3).

The origin of this selectivity enhancement remains unclear, however a number of possibilities occur. High hydrogen pressures may promote Pt nanoparticle restructuring with consequent changes in particle size or exposed facet. In situ XAS measurements by Mistry and co-workers revealed $1 \mathrm{~nm}$ platinum clusters underwent a $2 \mathrm{D} \rightarrow 3 \mathrm{D}$ transformation over $\gamma-\mathrm{Al}_{2} \mathrm{O}_{3}$ with increasing $p \mathrm{H}_{2} 1$ to 21 bar at room temperature ${ }^{58}$ : specifically, (111) bilayers were proposed to transform into cuboctahedra, which would represent a $70 \%$ loss of (111) facets at the expense of (100) facets ${ }^{59}$. Extended Hückel calculations by Delbecq and Sautet suggest that $\mathrm{Pt}(111)$ facets favour a di$\sigma_{\mathrm{CO}}$ CinnALD adsorption mode (and hence $\mathrm{C}=\mathrm{O}$ hydrogenation), whereas $\mathrm{Pt}(100)$ facets favour a co-planar $\eta_{4}$ mode and hence $\mathrm{C}=\mathrm{C}$ hydrogenation $^{44}$. For the work of Mistry et al., the high pressure hydrogen-induced switchover from (111) to (100) facets would be

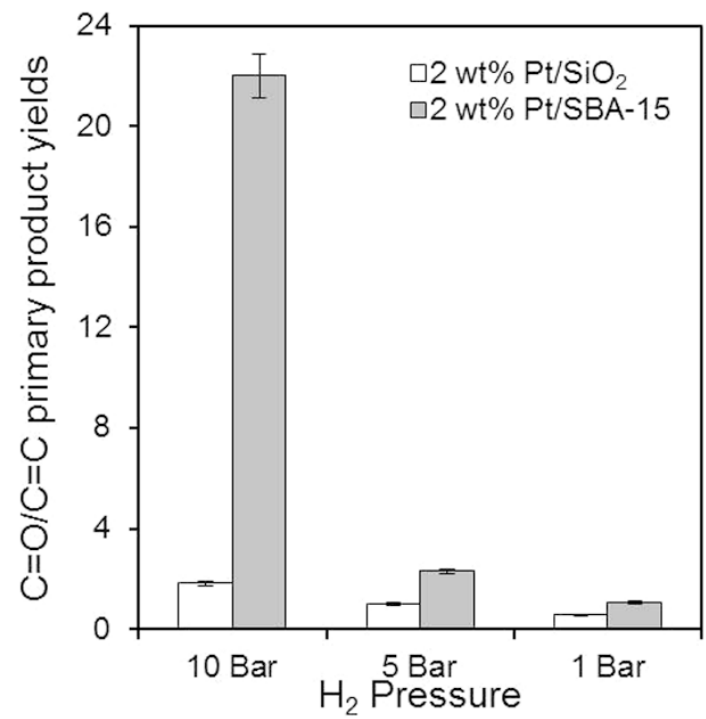

Figure 8 Hydrogen pressure dependence of $\mathrm{C}=\mathrm{O}$ versus $\mathrm{C}=\mathrm{C}$ hydrogenation pathways during CinnALD hydrogenation over 2 wt\% silica supported Pt catalysts.

predicted to lower selectivity to $\mathrm{CinnOH}$. In order to assess whether such restructuring could occur during high pressure CinnALD hydrogenation, we conducted in situ powder XRD of silica supported $2 \mathrm{wt} \% \mathrm{Pt}$ catalysts between atmospheric pressure and 7 bar. A small, but systematic fcc platinum lattice expansion $(\sim 0.0004 \mathrm{~nm} \cong 0.1 \%)$ was observed over both supports (Figure S15), being greater for the SBA-15 sample, and which proved largely reversible upon removing hydrogen. Such an expansion is ten times smaller than that observed during the analogous in situ XAS study of $\mathrm{Pt} / \gamma-\mathrm{Al}_{2} \mathrm{O}_{3}$, and the ratio of (111):(200) X-ray reflections was independent of hydrogen pressure, suggesting that hydrogen does not induce significant changes in either nanoparticle shape or size in the present work; this is hardly surprising considering that our $2 \mathrm{wt} \%$ catalysts comprise much larger particles of around $15 \mathrm{~nm}$, which thermodynamic calculations predict should exist as stable decahedra ${ }^{60,61}$. The magnitude of lattice expansions in Figure S15 are also much less than the 2-4\% calculated/experimentally observed for hydride formation ${ }^{62,63}$ or hydrogen chemisorption over strained sub-5 nm Pt nanoparticles ${ }^{64-66}$, wherein hydrogen e.g. weakens metal-support interactions, relaxing Pt-Pt distances for smaller particles towards the bulk value. It therefore seems highly unlikely that the selectivity enhancements observed in the present study are attributable to hydrogen-induced restructuring of $\mathrm{Pt}$, but rather a rise in hydrogen surface atom density $^{58}$; concomitant surface crowding destabilising the stericallydemanding $\eta_{4}$ di $-\sigma_{\mathrm{CO}}+\pi_{\mathrm{C}=\mathrm{C}}$ mode thus switching off the $\mathrm{C}=\mathrm{C}$ hydrogenation pathway. Vergunst et al. proposed a coverage dependent change in CinnALD adsorption mode from flat-lying $\eta_{2}$ di- $\sigma_{\mathrm{CC}}$ or $\eta_{4}$ di- $\sigma_{\mathrm{CO}}+\pi_{\mathrm{C}=\mathrm{C}}$ to carbonyl end-on adsorption $\eta_{2}$ di $-\sigma_{\mathrm{C}=\mathrm{O}}$ with increasing CinnALD coverage over $\mathrm{Pt} / \mathrm{C}^{49}$.

a-Methyl-trans-cinnamaldehyde hydrogenation. The preceding investigations revealed that destabilisation of $\mathrm{C}=\mathrm{C}$ relative to $\mathrm{C}=\mathrm{O}$ adsorption modes of CinnALD over platinum nanoparticles favour its selective hydrogenation to CinnOH. We therefore hypothesised that increasing the steric bulk around the alkene function for a fixed particle size and support polarity, should also hinder di $-\sigma_{\mathrm{CC}}$ or $\eta_{4}$ di- $\sigma_{\mathrm{CO}}+\pi_{\mathrm{C}=\mathrm{C}}$ adsorption and promote the formation of desirable unsaturated alcohols. $\alpha$-Methyl-transcinnamaldehyde (2-methyl-3-phenylacrolein) hydrogenation was consequently examined over low and high loading Pt nanoparticles supported on fumed silica and more polar SBA-15. The resulting selectivity to $\alpha$-methyl-trans-cinnamyl alcohol versus 2 -methyl-3- 
phenyl propanol/2-methyl-3-phenyl propionaldehyde was compared with that for CinnALD hydrogenation to $\mathrm{CinnOH}$ versus 3-phenyl propan-1-ol/3-phenyl propionaldehyde in Figure 9 , i.e. propensity for $\mathrm{C}=\mathrm{O}$ versus $\mathrm{C}=\mathrm{C}$ hydrogenation. The results of methyl substitution were striking, significantly favoring $\mathrm{C}=\mathrm{O}$ hydrogenation to the desired unsaturated alcohol product over $\mathrm{C}=\mathrm{C}$ hydrogenation to the unsaturated aldehyde/alcohol in all cases by $15-55 \%$. This enhancement was somewhat greater $(\sim 10 \%$ more) for larger nanoparticles, as anticipated due to increased steric hindrance around the $\mathrm{C}=\mathrm{C}$ center hindering close approach of the alkene function on extended platinum terraces. However, the impact of silica hydrophilicity was far more dramatic, with selectivity to $\alpha$-methyl-trans-cinnamyl alcohol enhanced by $\sim 30 \%$ over the polar SBA-15 relative to fumed silica, evidencing a strong support effect, with more hydrophobic allylic aldehydes preferentially orientated to favor $\mathrm{di}-\sigma_{\mathrm{CO}}$ adsorption on $\mathrm{Pt}$ nanoparticles dispersed on polar supports.

\section{Conclusions}

The liquid phase, selective hydrogenation of CinnALD to CinnOH over silica supported Pt nanoparticles strongly depends upon the physicochemical properties of the catalyst and reaction conditions. CinnALD hydrogenation is structure-insensitive with respect to metallic platinum, whereas high selectivity to desired CinnOH product requires large metal ensembles which favor $\mathrm{C}=\mathrm{O}$ versus $\mathrm{C}=\mathrm{C}$ hydrogenation. Support polarity also influences product selectivity, with a polar SBA-15 mesoporous silica proving superior to a weakly hydroxylated fumed, low area silica, the former enhancing $\mathrm{C}=\mathrm{O}$ hydrogenation to the unsaturated alcohol while suppressing its subsequent hydrogenation to 3-phenyl propan-1-ol. In situ ATR-IR surface sensitive spectroscopy implicates a change in CinnALD orientation over the more polar SBA-15 support as the origin of this enhanced selectivity. The generality of this phenomenon was established through the first systematic study of alkyl-substituted benzaldehydes, whose selective carbonyl hydrogenation was similarly promoted over SBA-15 with respect to fumed silica.

Increasing hydrogen pressures between $1 \rightarrow 10$ bar accelerated CinnALD hydrogenation over both silica supports. However high

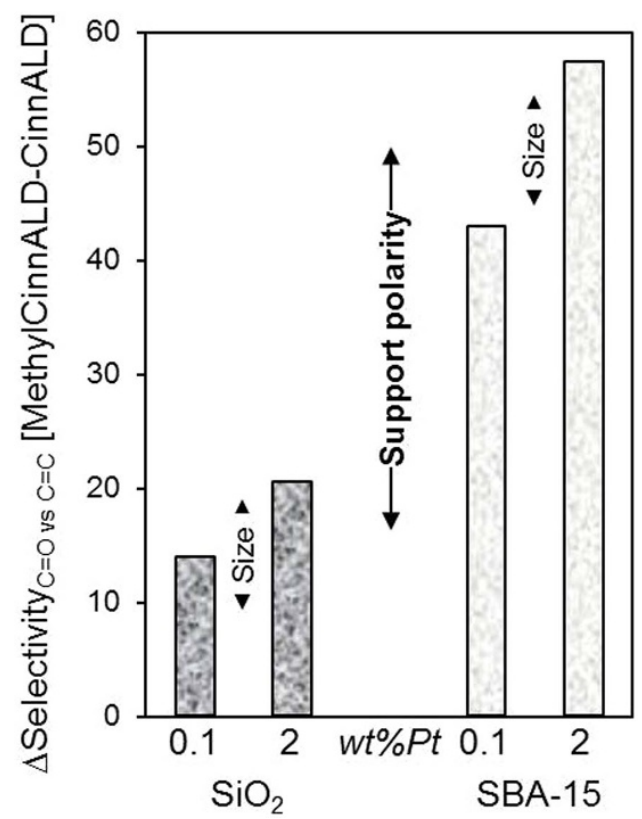

Figure 9| Impact of methyl substitution alpha to the carbonyl in CinnALD upon the rates of $\mathrm{C}=\mathrm{C}$ versus $\mathrm{C}=\mathrm{O}$ hydrogenation over small and large Pt nanoparticles supported on fumed or polar mesoporous SBA-15 silicas.
$\mathrm{pH}_{2}$ pressures also induced a dramatic switchover in CinnALD reaction pathway from predominantly $\mathrm{C}=\mathrm{C}(1 \mathrm{bar})$ to $>90 \% \mathrm{C}=\mathrm{O}$ hydrogenation (10 bar). In the absence of any apparent change in either platinum oxidation state or morphology, we attribute this significant promotion to the effects of surface crowding upon CinnALD adsorption, with less sterically-demanding $\eta_{2}$ di- $\sigma_{C=O}$ binding favored over di- $\sigma_{\mathrm{CC}}$ and $\eta 4 \mathrm{di}-\sigma_{\mathrm{CO}}+\pi_{\mathrm{C}=\mathrm{C}}$ modes. This hypothesis finds support from experiments on $\alpha$-methyl-trans-cinnamaldehyde, wherein methylation of the alkene function increases selective hydrogenation of the $\mathrm{C}=\mathrm{O}$ versus $\mathrm{C}=\mathrm{C}$ bond with respect to CinnALD, particularly over the polar SBA-15 support for which close approach of the aromatic and methylated alkene functions are disfavored.

Platinum-catalyzed chemoselective hydrogenation of unsaturated aldehydes requires careful tuning of metal particle size/oxidation state and support polarity, in concert with high hydrogen pressures in order to achieve high selectivity to the corresponding unsaturated alcohols.

\section{Methods}

Catalyst synthesis. SBA-15 was synthesised following the method of Stucky and coworkers ${ }^{34}$. Briefly, $10 \mathrm{~g}$ Pluronic P123 was dissolved in $75.5 \mathrm{~cm}^{3}$ water and $291.5 \mathrm{~cm}^{3}$ of $2 \mathrm{M}$ hydrochloric acid under stirring at $35^{\circ} \mathrm{C}$. Tetraethylorthosilicate $\left(15.5 \mathrm{~cm}^{3}\right)$ was subsequently added and left stirring for $20 \mathrm{~h}$. The resulting gel was aged for $24 \mathrm{~h}$ at $80^{\circ} \mathrm{C}$ without agitation. The solid was filtered, washed with $1000 \mathrm{~cm}^{3}$ water, and dried at room temp before calcination at $500^{\circ} \mathrm{C}$ for $6 \mathrm{~h}$ in $\operatorname{air}\left(\operatorname{ramp~} 1^{\circ} \mathrm{C} \cdot \mathrm{min}^{-1}\right)$. The resulting silica exhibited the expected ordered, hexagonal $(p 6 \mathrm{~mm})$ arrangements of monodispersed, uniform mesopores.

$2 \mathrm{~g}$ batches of mesoporous SBA-15 were wetted with $16 \mathrm{~cm}^{3}$ of aqueous ammonium tetrachloroplatinate (II) or tetraammine platinum (II) nitrate solutions (precursor concentrations adjusted to achieve nominal Pt loadings spanning 0.05 to 2 $\mathrm{wt} \%)$. Resulting slurries were stirred for $18 \mathrm{~h}$ at room temperature before heating to $50^{\circ} \mathrm{C}$. Agitation was ceased after $5 \mathrm{~h}$, and the solids dried for a further $24 \mathrm{~h}$ at $50^{\circ} \mathrm{C}$ to yield a powder. Powder samples were calcined at $500^{\circ} \mathrm{C}$ for $4 \mathrm{~h}$ in air $\left(1^{\circ} \mathrm{C} \cdot \mathrm{min}^{-1}\right.$ ramp rate), prior to reduction at $400^{\circ} \mathrm{C}$ for $2 \mathrm{~h}\left(10^{\circ} \mathrm{C} \cdot \mathrm{min}^{-1}\right.$ ramp rate $)$ under $10 \mathrm{~cm}^{3} \cdot \mathrm{min}^{-1}$ flowing hydrogen. $2 \mathrm{~g}$ batches of a mechanically compacted fumed silica $\left(\mathrm{SiO}_{2}, 200 \mathrm{~m}^{2} \mathrm{~g}^{-1} \mathrm{~S} 5505 \mathrm{Sigma}\right)$ were likewise wetted with $16 \mathrm{~cm}^{3}$ aqueous ammonium tetrachloroplatinate (II) or tetraammine platinum (II) nitrate solutions (precursor concentrations adjusted to achieve nominal Pt loadings spanning 0.05 to 2 $\mathrm{wt} \%)$, and the resulting slurries dried, calcined and reduced as above.

Characterization. Nitrogen porosimetry was undertaken on a Quantachrome Nova 4000 e porosimeter and analysed with NovaWin software version 11. Samples were degassed at $120^{\circ} \mathrm{C}$ for $2 \mathrm{~h}$ prior to analysis by nitrogen adsorption at $-196^{\circ} \mathrm{C}$. Adsorption/desorption isotherms were recorded for all parent and Pt-impregnated silicas. BET surface areas were calculated over the relative pressure range 0.01-0.2. Pore diameters and volumes were calculated by applying the BJH method to desorption isotherms for relative pressures $>0.35$. Low and wide angle XRD patterns were recorded on a PANalytical X'pertPro diffractometer fitted with an X'celerator detector and $\mathrm{Cu} \mathrm{K}_{\alpha}(1.54 \AA)$ source, calibrated against a silicon standard. Low angle patterns were recorded from $2 \theta=0.3-8^{\circ}$ with a step size of $0.01^{\circ}$, and wide angle patterns from $2 \theta=20-90^{\circ}$ with a step size of $0.02^{\circ}$. The Scherrer equation was used to calculate volume-averaged Pt crystallite diameters from broadening of the associated metal reflections. In situ XRD was conducted in an Anton Parr XRK900 cell on a Bruker

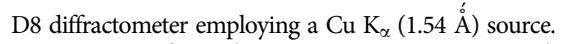

XPS was performed on a Kratos Axis HSi X-ray photoelectron spectrometer fitted with a charge neutralizer and magnetic focusing lens, employing $\mathrm{Al} \mathrm{K} \mathrm{K}_{\alpha}$ monochromated radiation $(1486.7 \mathrm{eV})$. Spectral fitting was performed using CasaXPS version 2.3.14. Binding energies were corrected to the $\mathrm{C} 1$ s peak at $284.6 \mathrm{eV}$ and surface atomic compositions calculated via correction for the appropriate instrument response factors. Pt 4f XP spectra were fitted using a common Gaussian-Lorentzian asymmetric lineshape. Errors were estimated by varying the Shirley backgroundsubtraction procedure and re-calculating component fits. Pt dispersions were measured via CO pulse chemisorption on a Quantachrome ChemBET 3000 system. Samples were outgassed at $150^{\circ} \mathrm{C}$ under flowing $\mathrm{He}\left(20 \mathrm{ml} \mathrm{min}^{-1}\right)$ for $1 \mathrm{~h}$, prior to reduction at $150^{\circ} \mathrm{C}$ under flowing hydrogen $\left(10 \mathrm{ml} \mathrm{min}^{-1}\right)$ for $1 \mathrm{~h}$ before room temperature analysis; this reduction protocol is milder than that employed during $\mathrm{Pt}$ impregnation, and does not induce particle sintering. $\mathrm{A} \mathrm{CO}: \mathrm{Pt}_{\text {surface }}$ stoichiometry of 0.68 was assumed, since the formation of a fully saturated monolayer is energetically unfavorable under the measurement conditions employed. DRIFTS measurements were conducted employing a Thermo Scientific Nicolet environmental cell and Smart Collector accessory on a Thermo Scientific Nicolet iS50 FT-IR Spectrometer with MCT detector. Samples were diluted in $\mathrm{KBr}(1: 9)$ and evacuated at $200^{\circ} \mathrm{C}$ for $2 \mathrm{~h}$ prior to in vacuo spectral acquisition. Attenuated total reflectance IR (ATR-IR) measurements were conducted employing a Pike 20 bounce HATR environmental flow cell and Thermo Scientific Avatar spectrometer with MCT detector and ZnSe ATR crystal. Catalyst films were deposited from aqueous slurries onto the ATR crystal and 
dried overnight at $40^{\circ} \mathrm{C}$ in vacuo. A $0.84 \mathrm{M}$ CinnALD in anisole solution was subsequently flowed over the dried catalyst film at $1 \mathrm{ml} . \mathrm{min}^{-1}$, and IR spectra recorded as a function of temperature during sample heating at $3^{\circ} \mathrm{C} \cdot \mathrm{min}^{-1}$ from room temperature to $90^{\circ} \mathrm{C}$. A liquid-phase vibrational spectrum of CinnALD was calculated for the geometry optimized structure using density functional theory as implemented through Gaussian 03 (Gaussian, Inc., Wallingford CT, 2004) using a 6-311 Gdp basis set and the B3LYP functional in order to aid and visualize spectral assignments.

SEM images were recorded on a Carl Zeiss Evo-40 SEM operating at $10 \mathrm{kV}$. Samples were supported on carbon tape. Metal loadings were determined using EDX analysis at $25 \mathrm{kV}$ with a maximum current of $25 \mathrm{nA}$ and working distance of $9 \mathrm{~mm}$. High resolution (S)TEM images were recorded on an FEI Tecnai F20 field emission gun TEM operated at $200 \mathrm{kV}$ equipped with a Gatan Orius SC600A CCD camera. Samples were prepared for TEM by dispersion in ethanol and drop-casting onto a copper grid coated with a continuous carbon support film (Agar Scientific Ltd). Images were analyzed in Image J 1.41. The Gaussian width of Pt nanoparticle size distributions from which mean values are reported in Figures 1-2 was only $\sim \pm 0.5 \mathrm{~nm}$, which does not represent a significant variance considering the overall size range spanned of 1.9-16 nm nor interferes with the size dependent selectivity and activity reported in this work.

Cinnamaldehyde hydrogenation. Catalyst testing was performed using a Radleys Starfish parallel reactor on a $10 \mathrm{~cm}^{3}$ scale at $90^{\circ} \mathrm{C} .100 \mathrm{mg}$ of catalyst were added to reaction mixtures containing $8.4 \mathrm{mmol}$ of aldehyde substrate in $10 \mathrm{~cm}^{3}$ anisole solvent, and $0.1 \mathrm{~cm}^{3}$ internal standard (mesitylene) at $90^{\circ} \mathrm{C}$ under $700 \mathrm{rpm}$ stirring and bubbling $\mathrm{H}_{2}\left(1 \mathrm{bar}, 5 \mathrm{~cm}^{3} \cdot \mathrm{min}^{-1}\right)$ which ensured the absence of external masstransport limitations. Reactivity of the $2 \mathrm{wt} \% \mathrm{Pt} / \mathrm{SBA}-15$ catalyst was also independent of silica particle size, confirming facile in-pore mass-transport (Table S4). The absolute Pt content varied between $0.26 \mu \mathrm{mol}$ ( $0.05 \mathrm{wt} \%$ catalysts) and $10.8 \mu \mathrm{mol}$ (for the highest loading $2.10 \mathrm{wt} \%$ ), corresponding to substrate:catalyst ratios ranging from $3.28 \times 10^{4}(0.05 \mathrm{wt} \%)$ down to $6.92 \times 10^{2}(2.1 \mathrm{wt} \%)$. Reactions were sampled periodically for kinetic profiling by off-line gas chromatography using a Varian 3800GC with 8400 autosampler fitted with a VF-5ms Factor Four column $(30 \mathrm{~m} \times 0.25 \mathrm{~mm} \times 0.25 \mu \mathrm{m})$. For CinnALD, catalytic hydrogenation of the likely reaction intermediates 3-phenyl propan-1-ol, 3-phenyl propionaldehyde, 3-phenyl propanoic acid, cinnamic acid and $\mathrm{CinnOH}$ was also measured for the lowest and highest Pt loadings ( 0.05 and $2.1 \mathrm{wt} \%$ ) on both silicas under identical conditions to those employed for CinnALD hydrogenation. The role of hydrogen pressure was investigated keeping other reaction conditions (temperature, internal standard and substrate:catalyst ratio) identical, within a stirred Parr $5513100 \mathrm{ml}$ stainless steel autoclave between 1 and 10 bar $\mathrm{H}_{2}$ pressure; activity and selectivity were assessed through periodic sampling via a dip-tube. Control experiments verified negligible substrate conversion in the absence of either $\mathrm{H}_{2}$ or platinum catalyst, while hot filtration tests evidenced no detectable metal leaching, confirming the heterogeneous nature of the observed reactions. Quoted activities and selectivities are the mean of duplicate or triplicate reactions with errors $\pm 2 \%$; mass balances $>95 \%$ in all cases. Conversion, selectivity, yield and TOF were defined as below:

$$
\% \text { Conversion }=\left\{\left(\left[\text { Aldehyde }_{\mathrm{t}=0}\right]-\left[\text { Aldehyde }_{\mathrm{t}=\mathrm{x}}\right]\right) /\left[\text { Aldehyde }_{\mathrm{t}=0}\right]\right\} \times 100
$$

$\%$ Selectivity $=\left\{\left[\right.\right.$ Product $\left.1_{\mathrm{t}=\mathrm{x}}\right] /\left(\left[\right.\right.$ Product $\left.1_{\mathrm{t}=\mathrm{x}}\right]+\left[\right.$ Product $\left.\left.\left.2_{\mathrm{t}=\mathrm{x}}\right]+\ldots\right)\right\} \times 100$

$$
\% \text { Yield }=\{\% \text { Conversion } \times \% \text { Selectivity }\} / 100
$$

$\mathrm{TOF}=\mathrm{mmols}_{\mathrm{CinnALD}}$ converted $\cdot \mathrm{h}^{-1} / \mathrm{mmols}$ surface

Pt determined by $\mathrm{CO}$ chemisorption

1. Trost, B. M. \& Kulawiec, R. J. Chemoselectivity in the ruthenium-catalyzed redox isomerization of allyl alcohols. Journal of the American Chemical Society 115 2027-2036, doi:10.1021/ja00058a059 (1993).

2. Breit, B. \& Seiche, W. Recent advances on chemo-, regio- and stereoselective hydroformylation. Synthesis, 1-36; doi:10.1055/s-2001-9739 (2001).

3. Fiori, K. W. \& Du Bois, J. Catalytic intermolecular amination of C-H bonds: Method development and mechanistic insights. Journal of the American Chemical Society 129, 562-568, doi:10.1021/ja0650450 (2007).

4. Magano, J. \& Dunetz, J. R. Large-Scale Carbonyl Reductions in the Pharmaceutical Industry. Organic Process Research \& Development 16, 1156-1184, doi:10.1021/op2003826 (2012).

5. Hellal, M., Falk, F. C., Wolf, E., Dryzhakov, M. \& Moran, J. Breaking the dichotomy of reactivity vs. chemoselectivity in catalytic SN1 reactions of alcohols. Organic \& Biomolecular Chemistry 12, 5990-5994, doi:10.1039/C4OB01265H (2014).

6. Sheldon, R. A., Arends, I., Ten Brink, G. J. \& Dijksman, A. Green, catalytic oxidations of alcohols. Accounts Chem. Res. 35, 774-781, doi:10.1021/ar010075n (2002).

7. Clark, J. H. Solid acids for green chemistry. Accounts Chem. Res. 35, 791-797, doi:10.1021/ar010072a (2002).
8. Sheldon, R. A., Arends, I. W. C. E. \& Hanefeld, U. in Green Chemistry and Catalysis 1-47 (Wiley-VCH Verlag GmbH \& Co. KGaA, 2007).

9. Blaser, H. U. et al. Selective hydrogenation for fine chemicals: Recent trends and new developments. Adv. Synth. Catal. 345, 103-151, doi:10.1002/adsc. 200390000 (2003).

10. Gallezot, P. \& Richard, D. Selective Hydrogenation of $\alpha, \beta$-Unsaturated Aldehydes. Catalysis Reviews 40, 81-126, doi:10.1080/01614949808007106 (1998).

11. Maki-Arvela, P., Hajek, J., Salmi, T. \& Murzin, D. Y. Chemoselective hydrogenation of carbonyl compounds over heterogeneous catalysts. Appl. Catal. A-Gen. 292, 1-49, doi:10.1016/j.apcata.2005.05.045 (2005).

12. Kliewer, C. J., Bieri, M. \& Somorjai, G. A. Hydrogenation of the $\alpha, \beta$-Unsaturated Aldehydes Acrolein, Crotonaldehyde, and Prenal over Pt Single Crystals: A Kinetic and Sum-Frequency Generation Vibrational Spectroscopy Study. Journal of the American Chemical Society 131, 9958-9966, doi:10.1021/ja8092532 (2009).

13. Lee, I., Delbecq, F., Morales, R., Albiter, M. A. \& Zaera, F. Tuning selectivity in catalysis by controlling particle shape. Nat Mater 8, 132-138 (2009).

14. Attard, G. A. et al. Semi-hydrogenation of alkynes at single crystal, nanoparticle and biogenic nanoparticle surfaces: the role of defects in Lindlar-type catalysts and the origin of their selectivity. Faraday Discussions 162, 57-75, doi:10.1039/ C3FD00007A (2013).

15. An, K. et al. Preparation of mesoporous oxides and their support effects on $\mathrm{Pt}$ nanoparticle catalysts in catalytic hydrogenation of furfural. Journal of Colloid and Interface Science 392, 122-128, doi:http://dx.doi.org/10.1016/j.jcis.2012.10. 029 (2013).

16. Poupin, C., Maache, R., Pirault-Roy, L., Brahmi, R. \& Williams, C. T. Effect of $\mathrm{Al} 2 \mathrm{O} 3 / \mathrm{MgO}$ molar ratio on catalytic performance of $\mathrm{Pt} / \mathrm{MgO}-\mathrm{Al} 2 \mathrm{O} 3$ catalyst in acetonitrile hydrogenation followed by Fourier transform infrared spectroscopy. Applied Catalysis A: General 475, 363-370, doi:http://dx.doi.org/10.1016/j.apcata. 2014.01.041 (2014)

17. Lara, P., Suárez, A., Collière, V., Philippot, K. \& Chaudret, B. Platinum NHeterocyclic Carbene Nanoparticles as New and Effective Catalysts for the Selective Hydrogenation of Nitroaromatics. Chem CatChem 6, 87-90, doi:10.1002/cctc.201300821 (2014).

18. Li, S., Boucheron, T., Tuel, A., Farrusseng, D. \& Meunier, F. Size-selective hydrogenation at the subnanometer scale over platinum nanoparticles encapsulated in silicalite-1 single crystal hollow shells. Chemical Communications 50, 1824-1826, doi:10.1039/C3CC48648F (2014).

19. Saudan, L. A. Hydrogenation Processes in the Synthesis of Perfumery Ingredients. Accounts Chem. Res. 40, 1309-1319, doi:10.1021/ar700140m (2007).

20. Oduro, W. O., Cailuo, N., Yu, K. M., Yang, H. \& Tsang, S. C. Geometric and electronic effects on hydrogenation of cinnamaldehyde over unsupported Ptbased nanocrystals. Physical chemistry chemical physics : PCCP 13, 2590-2602, doi:10.1039/c0cp01832e (2011).

21. Tsang, S. C. et al. Engineering Preformed Cobalt-Doped Platinum Nanocatalysts For Ultraselective Hydrogenation. ACS Nano 2, 2547-2553, doi:10.1021/ nn800400u (2008).

22. Zhu, Y. \& Zaera, F. Selectivity in the catalytic hydrogenation of cinnamaldehyde promoted by $\mathrm{Pt} / \mathrm{SiO} 2$ as a function of metal nanoparticle size. Catalysis Science \& Technology 4, 955-962, doi:10.1039/C3CY01051A (2014).

23. Silva, A. \& Fouilloux, P. Effect of metal-support interaction during selective hydrogenation of cinnamaldehyde to cinnamyl alcohol on Pt-based bimetallic catalysts. Applied Catalysis A: General 148, 253-264 (1997).

24. Zheng, R. et al. Controlling hydrogenation of $\mathrm{CO}$ and $\mathrm{CC}$ bonds in cinnamaldehyde using silica supported $\mathrm{Co}-\mathrm{Pt}$ and $\mathrm{Cu}-\mathrm{Pt}$ bimetallic catalysts. Applied Catalysis A: General 419-420, 126-132, doi:10.1016/j.apcata.2012.01.019 (2012)

25. Urquhart, A. J., Williams, F. J., Vaughan, O. P., Cropley, R. L. \& Lambert, R. M. Adsorbate conformation determines catalytic chemoselectivity: crotonaldehyde on the Pt(111) surface. Chem Commun (Camb), 1977-1979, doi:10.1039/ b500590f (2005).

26. de Jesús, J. C. \& Zaera, F. Adsorption and thermal chemistry of acrolein and crotonaldehyde on Pt (111) surfaces. Surface science 430, 99-115 (1999).

27. Marshall, S. T. et al. Controlled selectivity for palladium catalysts using selfassembled monolayers. Nature materials 9, 853-858 (2010).

28. Kahsar, K. R., Schwartz, D. K. \& Medlin, J. W. Control of Metal Catalyst Selectivity through Specific Noncovalent Molecular Interactions. Journal of the American Chemical Society 136, 520-526, doi:10.1021/ja411973p (2013).

29. Guo, Z. et al. Pt Nanoclusters Confined within Metal-Organic Framework Cavities for Chemoselective Cinnamaldehyde Hydrogenation. ACS Catalysis, 1340-1348, doi:10.1021/cs400982n (2014).

30. Ji, X. et al. Selective Hydrogenation of Cinnamaldehyde to Cinnamal Alcohol over Platinum/Graphene Catalysts. ChemCatChem, n/a-n/a, doi:10.1002/ cctc.201402573 (2014).

31. Abid, M., Paul-Boncour, V. \& Touroude, R. Pt/CeO2 catalysts in crotonaldehyde hydrogenation: Selectivity, metal particle size and SMSI states. Applied Catalysis A: General 297, 48-59, doi:http://dx.doi.org/10.1016/j.apcata.2005.08.048 (2006).

32. Bailon-Garcia, E., Carrasco-Marin, F., Perez-Cadenas, A. F. \& Maldonado-Hodar, F. J. Microspheres of carbon xerogel: An alternative Pt-support for the selective hydrogenation of citral. Appl. Catal. A-Gen. 482, 318-326, doi:10.1016/ j.apcata.2014.06.011 (2014). 
33. Santiago-Pedro, S., Tamayo-Galván, V. \& Viveros-García, T. Effect of the acidbase properties of the support on the performance of Pt catalysts in the partial hydrogenation of citral. Catalysis Today 213, 101-108 (2013).

34. Zhao, D. et al. Triblock Copolymer Syntheses of Mesoporous Silica with Periodic 50 to 300 Angstrom Pores. Science 279, 548-552, doi:10.1126/ science.279.5350.548 (1998).

35. Parlett, C. M. A., Bruce, D. W., Hondow, N. S., Lee, A. F. \& Wilson, K. SupportEnhanced Selective Aerobic Alcohol Oxidation over Pd/Mesoporous Silicas. ACS Catalysis 1, 636-640, doi:10.1021/cs200145n (2011).

36. Kaneko, S. et al. Pt dispersion control in $\mathrm{Pt} / \mathrm{SiO} 2$ by calcination temperature using chloroplatinic acid as catalyst precursor. Applied Catalysis A: General 427-428, 85-91, doi:http://dx.doi.org/10.1016/j.apcata.2012.03.033 (2012).

37. Plomp, A. J., Vuori, H., Krause, A. O. I., de Jong, K. P. \& Bitter, J. H. Particle size effects for carbon nanofiber supported platinum and ruthenium catalysts for the selective hydrogenation of cinnamaldehyde. Applied Catalysis A: General 351, 9-15, doi:http://dx.doi.org/10.1016/j.apcata.2008.08.018 (2008).

38. Galvagno, S. \& Capannelli, G. Hydrogenation of cinnamaldehyde over Ru/C catalysts: effect of Ru particle size. Journal of Molecular Catalysis 64, 237-246 (1991).

39. Neri, G., Bonaccorsi, L. \& Galvagno, S. Kinetic Analysis of Cinnamaldehyde Hydrogenation over Alumina-Supported Ruthenium Catalysts. Industrial \& Engineering Chemistry Research 36, 3554-3562, doi:10.1021/ie9607457 (1997).

40. Nitta, Y., Ueno, K. \& Imanaka, T. Selective hydrogenation of $\alpha \beta$-unsaturated aldehydes on cobaltsilica catalysts obtained from cobalt chrysotile. Applied Catalysis 56, 9-22 (1989).

41. Prashar, A. K., Mayadevi, S. \& Nandini Devi, R. Effect of particle size on selective hydrogenation of cinnamaldehyde by Pt encapsulated in mesoporous silica. Catalysis Communications 28, 42-46, doi:10.1016/j.catcom.2012.08.017 (2012).

42. Gallezot, P., Giroir-Fendler, A. \& Richard, D. Chemioselectivity in cinnamaldehyde hydrogenation induced by shape selectivity effects in Pt-Y zeolite catalysts. Catal Lett 5, 169-174, doi:10.1007/BF00763949 (1990).

43. Englisch, M., Jentys, A. \& Lercher, J. A. Structure sensitivity of the hydrogenation of crotonaldehyde over $\mathrm{Pt} / \mathrm{SiO} 2$ and $\mathrm{Pt} / \mathrm{TiO} 2$. Journal of Catalysis 166, 25-35 (1997).

44. Delbecq, F. \& Sautet, P. Competitive C-C and C-O Adsorption of $\alpha-\beta$ Unsaturated Aldehydes on Pt and Pd Surfaces in Relation with the Selectivity of Hydrogenation Reactions: A Theoretical Approach. Journal of Catalysis 152, 217-236, doi:http://dx.doi.org/10.1006/jcat.1995.1077 (1995).

45. Ide, M. S., Hao, B., Neurock, M. \& Davis, R. J. Mechanistic Insights on the Hydrogenation of $\alpha, \beta$-Unsaturated Ketones and Aldehydes to Unsaturated Alcohols over Metal Catalysts. ACS Catalysis 2, 671-683, doi:10.1021/cs200567z (2012).

46. Handjani, S. et al. Influence of the support composition and acidity on the catalytic properties of mesoporous SBA-15, Al-SBA-15, and Al2O 3-supported Pt catalysts for cinnamaldehyde hydrogenation. Journal of Catalysis 282, 228-236 (2011).

47. Breen, J. P., Burch, R., Gomez-Lopez, J., Griffin, K. \& Hayes, M. Steric effects in the selective hydrogenation of cinnamaldehyde to cinnamyl alcohol using an $\mathrm{Ir} / \mathrm{C}$ catalyst. Applied Catalysis A: General 268, 267-274, doi:http://dx.doi.org/10.1016/ j.apcata.2004.04.002 (2004).

48. Zhu, Y. \& Zaera, F. Selectivity in the catalytic hydrogenation of cinnamaldehyde promoted by $\mathrm{Pt} / \mathrm{SiO} 2$ as a function of metal nanoparticle size. Catalysis Science \& Technology, doi:10.1039/C3CY01051A (2014).

49. Vergunst, T., Kapteijn, F. \& Moulijn, J. A. Kinetics of cinnamaldehyde hydrogenation-concentration dependent selectivity. Catalysis Today $\mathbf{6 6}$ 381-387, doi:http://dx.doi.org/10.1016/S0920-5861(00)00634-9 (2001).

50. Toebes, M. L. et al. Support effects in hydrogenation of cinnamaldehyde over carbon nanofiber-supported platinum catalysts: Kinetic modeling. Chemical Engineering Science 60, 5682-5695, doi:http://dx.doi.org/10.1016/j.ces.2005.05. 031 (2005).

51. Laref, S., Delbecq, F. \& Loffreda, D. Theoretical elucidation of the selectivity changes for the hydrogenation of unsaturated aldehydes on $\mathrm{Pt}(1 \& \# \mathrm{xa} 0 ; 1 \& \# \mathrm{xa0}$;1). Journal of Catalysis 265, 35-42, doi:http://dx.doi.org/10. 1016/j.jcat.2009.04.010 (2009).

52. Szöllösi, G., Török, B., Baranyi, L. \& Bartók, M. Chemoselective hydrogenation of cinnamaldehyde to cinnamyl alcohol over Pt/K-10 catalyst. Journal of Catalysis 179, 619-623 (1998)

53. Senthil Kumar, S. M., Soler Herrero, J., Irusta, S. \& Scott, K. The effect of pretreatment of Vulcan XC-72R carbon on morphology and electrochemical oxygen reduction kinetics of supported Pd nano-particle in acidic electrolyte. Journal of Electroanalytical Chemistry 647, 211-221, doi:http://dx.doi.org/10. 1016/j.jelechem.2010.05.021 (2010).

54. Christy, A. A. New insights into the surface functionalities and adsorption evolution of water molecules on silica gel surface: A study by second derivative near infrared spectroscopy. Vibrational Spectroscopy 54, 42-49, doi:http://dx.doi. org/10.1016/j.vibspec.2010.06.003 (2010).

55. Isaienko, O. \& Borguet, E. Hydrophobicity of Hydroxylated Amorphous Fused Silica Surfaces. Langmuir 29, 7885-7895, doi:10.1021/la401259r (2013).
56. Vasiur Rahaman, M. \& Albert Vannice, M. The hydrogenation of toluene and om-, and pxylene over palladium: I. Kinetic behavior and o-xylene isornerization. Journal of Catalysis 127, 251-266, doi:http://dx.doi.org/10.1016/00219517(91)90224-R (1991).

57. Keane, M. A. Gas phase hydrogenation/hydrogenolysis of benzaldehyde and otolualdehyde over Ni/SiO2. Journal of Molecular Catalysis A: Chemical 118, 261-269, doi:http://dx.doi.org/10.1016/S1381-1169(96)00386-X (1997).

58. Mistry, H., Behafarid, F., Bare, S. R. \& Roldan Cuenya, B. Pressure-Dependent Effect of Hydrogen Adsorption on Structural and Electronic Properties of Pt $/ \gamma$ Al2O3 Nanoparticles. ChemCatChem 6, 348-352, doi:10.1002/cctc.201300783 (2014).

59. Barnard, A. S. Useful equations for modeling the relative stability of common nanoparticle morphologies. Computer Physics Communications 182, 11-13, doi:http://dx.doi.org/10.1016/j.cpc.2010.07.034 (2011).

60. Baletto, F. \& Ferrando, R. Structural properties of nanoclusters: Energetic, thermodynamic, and kinetic effects. Reviews of Modern Physics 77, 371-423 (2005).

61. Xia, Y., Xiong, Y., Lim, B. \& Skrabalak, S. E. Shape-Controlled Synthesis of Metal Nanocrystals: Simple Chemistry Meets Complex Physics? Angewandte Chemie International Edition 48, 60-103, doi:10.1002/anie.200802248 (2009).

62. Isobe, Y., Yamauchi, M., Ikeda, R. \& Kitagawa, H. A study on hydrogen adsorption of polymer protected Pt nanoparticles. Synth. Met. 135, 757-758, doi:10.1016/ s0379-6779(02)00835-4 (2003).

63. Hakamada, M., Furukawa, T., Yamamoto, T., Takahashi, M. \& Mabuchi, M. Abnormal Hydrogen Absorption/Desorption Properties of Nanoporous Pt with Large Lattice Strains. Mater. Trans. 52, 806-809, doi:10.2320/ matertrans.M2010403 (2011)

64. Ramaker, D. E., Mojet, B. L., Garriga Oostenbrink, M. T., Miller, J. T. \& Koningsberger, D. C. Contribution of shape resonance and Pt-H EXAFS in the Pt L2,3 X-ray absorption edges of supported Pt particles: Application and consequences for catalyst characterization. Phys. Chem. Chem. Phys. 1, 2293-2302; doi:10.1039/A900716D (1999).

65. Ankudinov, A. L., Rehr, J. J., Low, J. \& Bare, S. R. Effect of Hydrogen Adsorption on the X-Ray Absorption Spectra of Small Pt Clusters. Physical Review Letters 86, 1642-1645 (2001).

66. Lei, Y., Jelic, J., Nitsche, L., Meyer, R. \& Miller, J. Effect of Particle Size and Adsorbates on the L3, L2 and L1 X-ray Absorption Near Edge Structure of Supported Pt Nanoparticles. Top Catal 54, 334-348, doi:10.1007/s11244-011 9662-5 (2011).

\section{Acknowledgments}

We thank the EPSRC (EP/G007594/4) for financial support and a Leadership Fellowship (AFL), and the Royal Society for the award of an Industry Fellowship (KW). Electron microscopy access was provided through the Leeds EPSRC Nanoscience and Nanotechnology Research Equipment Facility (LENNF) (EP/K023853/1). We thank Miss Brunella Barbero (EBRI) for her assistance with ATR measurements.

\section{Author contributions}

A.F.L. and K.W. conceived the research programme. L.J.D. synthesized all catalysts, conducted porosimetry, D.R.I.F.T.S., A.T.R.-I.R., X.R.D. and X.P.S. characterization, and performed all hydrogenation reactions. N.S.H. undertook HRTEM measurements and assisted with analysis. C.M.A.P. assisted with the design and analysis of DRIFTS experiments. M.A.I. assisted with XPS measurements and analysis. The manuscript was written through contributions of all authors.

\section{Additional information}

Supporting information Additional structural characterization of parent silica supports and Pt impregnated silicas and associated reaction profiles and kinetic data for CinnALD hydrogenation.

Supplementary information accompanies this paper at http://www.nature.com/ scientificreports

Competing financial interests: The authors declare no competing financial interests.

How to cite this article: Durndell, L.J. et al. Selectivity control in Pt-catalyzed cinnamaldehyde hydrogenation. Sci. Rep. 5, 9425; DOI:10.1038/srep09425 (2015).

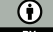

This work is licensed under a Creative Commons Attribution 4.0 International License. The images or other third party material in this article are included in the article's Creative Commons license, unless indicated otherwise in the credit line; if the material is not included under the Creative Commons license, users will need to obtain permission from the license holder in order to reproduce the material. To view a copy of this license, visit http://creativecommons.org/licenses/by/4.0/ 